\title{
Effects of CYP3A5 Polymorphisms on Efficacy and Safety of Tacrolimus Therapy in Patients with Idiopathic Membranous Nephropathy
}

This article was published in the following Dove Press journal: Pharmacogenomics and Personalized Medicine

\author{
Chengning Zhang ${ }^{1} *$ \\ Suyan Duan ${ }^{\mathrm{l}}$ * \\ Miao Guo ${ }^{2}$ \\ Yanggang Yuan' \\ Zhimin Huang' \\ Jingfeng Zhu' \\ Bin Sun' \\ Bo Zhang' \\ Changying Xing' \\ 'Departments of Nephrology, \\ ${ }^{2}$ Department of Pharmacy, The First \\ Affiliated Hospital of Nanjing Medical \\ University, Nanjing, Jiangsu 210029, \\ People's Republic of China \\ *These authors contributed equally to \\ this work
}

Correspondence: Changying Xing Department of Nephrology, The First Affiliated Hospital of Nanjing Medical University, Jiangsu Province Hospital, 300 Guangzhou Road, Nanjing 210029, Jiangsu Province, People's Republic of China $\mathrm{Tel} / \mathrm{Fax}+86-25-6830-6462$

Email cyxing62@I26.com
Background: Tacrolimus (TAC) is beneficial for patients with idiopathic membranous nephropathy (IMN). It has a narrow therapeutic concentration range and many factors influence TAC blood concentration. CYP3A5 is the most important enzyme in TAC metabolism. The aim of this study was to analyze the effects of CYP3A5 gene polymorphisms on the efficacy and safety of TAC in IMN patients.

Patients and Methods: Patients with IMN who received oral TAC $(0.05-0.075 \mathrm{mg} / \mathrm{kg} / \mathrm{day})$ combined with prednisone $(0.5 \mathrm{mg} / \mathrm{kg} /$ day $)$ from March 2016 to October 2018 were included. The data of clinical characteristics, therapeutic drugs and adverse reactions of patients were collected at baseline and during 24 weeks of treatment. Patients were divided into two groups according to different CYP3A5 genetic polymorphisms. The significant differences in the efficacy and side effects between the two groups were analyzed.

Results: A total of 76 patients who completed follow-up were divided into CYP3A5 nonexpresser $(\mathrm{CYP} 3 \mathrm{~A} 5 * 3 / * 3)$ group and CYP3A5 expresser (CYP3A5*1/*3) group. The significant association between the CYP3A5 phenotype and TAC metabolism was observed. A total of 43 case-times patients exhibited adverse effects. The infection rate in CYP3A5 nonexpresser group (21.95\%) was remarkably higher than the rate in CYP3A5 expresser group (5.71\%). Blood concentration and $\mathrm{C}_{0} / \mathrm{D}$ levels were risk factors for adverse events through logistic regression analysis. There was no statistical difference between the study groups with respect to the efficacy. Conclusion: Our results demonstrated that CYP3A5 polymorphisms had important guiding roles in the treatment of IMN with tacrolimus. CYP3A5 expressers required higher daily doses of TAC to achieve the target drug concentration, but with fewer side effects. CYP3A5 genetic polymorphism might be used for TAC dosing adjustment to optimize the treatment for patients with IMN.

Keywords: CYP3A5 polymorphisms, idiopathic membranous nephropathy, tacrolimus, side effects

\section{Introduction}

Idiopathic membranous nephropathy (IMN) is one of the most common causes of nephrotic syndrome (NS) in adults and accounts for $9.89-13.3 \%$ of primary glomerular disease in mainland China. ${ }^{1,2}$ IMN is characterized by immune complex deposition under glomerular epithelial cells; thus, leading to diffuse thickening of capillary basement membranes.

Ponticelli regimen, a 6-month cycling of an alkylating agent with corticosteroids, is the preferred protocol recommended for IMN by the KDIGO Clinical Practice Guidelines 
because there is evidence to support its relationship with longterm improvement of renal survival. ${ }^{3}$ However, adverse events are common in this protocol. ${ }^{4,5}$ Calcineurin inhibitors (CNIs) are the only other level I treatment recommendation in the glomerular nephropathy (GN) guidelines for IMN patients who refused/failed cyclophosphamide/steroid therapy or had contraindications to this approach. Many important trials have been conducted, which have better defined the role of CNIs for the treatment of MN. ${ }^{6,7}$ Howman et al reported a UK randomised controlled trial in IMN which was restricted to patients with a rapid progressive decrease of $>20 \%$ in eGFR within 2 years of entry. In the intention-to-treat analysis only, the alkylating/steroid regimens showed benefit when compared with CNI group or placebo, but overall patient survival showed no significant differences between groups. There was a substantial serious adverse event (AE) rate in all groups, highest in the chlorambucil/steroid group. ${ }^{6,8}$ The other one is the MENTOR trial in IMN patients with persistent proteinuria $>5 \mathrm{~g} /$ day comparing cyclosporine monotherapy with rituximab, which showed that rituximab was noninferior to $\mathrm{CNI}$ in inducing complete or partial remission of proteinuria at 12 months. $^{7}$ RCTs have demonstrated reductions in proteinuria similar in degree to other regimens but an earlier and higher relapse rate for CNIs. ${ }^{9,10}$ Therefore, the dosage of CNIs treatment needs to be weighed among benefits, the adverse events and relapse risks. Tacrolimus (TAC) is one of the CNIs, which has been widely used in autoimmune diseases and the prevention of rejection in liver and kidney transplantation. TAC inhibits the activation of an essential transcription factor for the expression of cytokine genes in T cells, leading to the decreased production of cytokines such as interleukin- 2 and interferon- $\gamma .{ }^{11}$ In recent years, TAC has been used more frequently for the treatment of IMN because of the stronger immunosuppressive effect and fewer side effects compared with cyclosporine. Due to the narrow therapeutic range, therapeutic drug monitoring (TDM) is essential for the optimization of TAC dosage and the prevention of adverse effects. Achieving the therapeutic level is especially important during the initial therapy of IMN.

The cytochrome $\mathrm{P} 450$ protein, especially the CYP3A4/5 subfamily, is the most important enzyme in TAC metabolism and is expressed mainly in the liver, intestine and kidney. The previous study showed that the CYP3A5*3 SNP (6986 A>G) in intron 3 was strongly associated with CYP3A5 expression, and the effect of the CYP3A $5 * 3$ allele on the pharmacokinetics of oral TAC was confirmed by consistent positive results. ${ }^{12}$ Allele carriers of the CYP3A5*1 (CYP3A5*1/*1 or CYP3A5 *1/*3, CYP3A5 expresser) produce higher levels of functional CYP3A5 compared with homozygous carriers of CYP3A5*3
(CYP3A5*3/*3, CYP3A5 nonexpresser), which may require higher doses of TAC to achieve a similar therapeutic concentration. ${ }^{13}$ Studies in renal transplant recipients have demonstrated that patients who did not express functional CYP3A5 (CYP3A5 nonexpresser) required significantly less TAC to reach target concentrations compared to patients who expressed CYP3A5 (CYP3A5 expresser, requiring 30-50\% higher TAC doses). ${ }^{14}$ However, at present, the studies are mainly limited to renal transplantation. We performed this retrospective study to investigate the influence of CYP3A5 gene polymorphisms on the efficacy and side effects of TAC treatment in patients with IMN.

\section{Patients and Methods}

\section{Patients}

This study was approved by the Ethics Committee of the First Affiliated Hospital of Nanjing Medical University (No.2018SR-218.A1). All procedures followed were in accordance with the ethical principles of Good Clinical and Laboratory Practices and with the Helsinki Declaration of 1975, as revised in 2008. Written informed consent was obtained from all patients enrolled. Patients with biopsy-proven IMN who were hospitalized in the First Affiliated Hospital of Nanjing Medical University from March 2016 to October 2018 were screened in this retrospective study. Inclusion criteria for collecting patients' data were as follows: (1) pathology-proven IMN; (2) serum creatinine $<260 \mu \mathrm{mol} / \mathrm{L}$; (3) no administration of CYP3A enzyme inducers or inhibitors (such as macrolides, rifampicin, diltiazem, antifungal drugs, etc.) were administered in the previous 1 month. Exclusion criteria: (1) secondary membranous nephropathy; (2) malignant tumor and human immunodeficiency virus (HIV), hepatitis B virus (HBV), or hepatitis $\mathrm{C}$ virus (HCV) infection; (3) receiving other cytotoxic drugs or immunosuppressive agents in the previous 1 month; (4) pregnancy or lactation; (5) liver dysfunction (aspartate aminotransferase or alanine aminotransferase twice the upper limit of the normal value) or bilirubin twice the upper limit of the normal value.

\section{Therapy}

The safety and efficacy of initial TAC combined with prednisone therapy were explored in this 24-week study. Patients initially received TAC $(0.05-0.075 \mathrm{mg} / \mathrm{kg} /$ day $)$ combined with prednisone $(0.5 \mathrm{mg} / \mathrm{kg} /$ day $)$. TAC was administered orally every $12 \mathrm{hrs}$ ( $1 \mathrm{hr}$ before meals or $2 \mathrm{hrs}$ after meals). The whole-blood concentration of TAC was measured using the ARCHITECT TAC Reagent Kit (Chemiluminescence 
microparticle immunoassay) (Abbott Laboratories, IL, USA) according to the manufacturer's protocol. The TAC blood concentration was measured and dosage was then adjusted weekly by blood concentration with a target range of 4-10ng/ $\mathrm{mL} .{ }^{15}$ After 8 weeks of initial administration, the prednisone dosage tapered by $5 \mathrm{mg}$ every 2 weeks until daily maintenance of $10 \mathrm{mg}$ per day.

\section{Observation Indicators}

Patients were followed-up once a week in the first month and once a month for the next 5 months. The following variables were measured at baseline and during observation time: TAC dose (D), TAC blood concentration, blood routine (white blood cell count, red blood cell count, hemoglobin and platelet), 24 hrs urine excretion, serum albumin, liver function (alanine aminotransferase, aspartate aminotransferase), renal function (blood urea nitrogen, serum creatinine, serum uric acid), blood lipids (total cholesterol, triglyceride), fasting blood glucose and estimated glomerular filtration rate (eGFR) calculated by Chronic Kidney Disease Epidemiology Collaboration (CKDEPI) equation. TAC dose-adjusted trough concentration $\left(\mathrm{C}_{0} / \mathrm{D}\right.$ ratio) was calculated as trough concentration $(\mathrm{ng} / \mathrm{mL})$ divided by the corresponding weight-adjusted daily dose ( $\mathrm{mg} / \mathrm{kg} / \mathrm{d})$. At the same time, the occurrences of adverse events during the treatment, such as hyperglycemia, tremor, headache, kidney injury, liver damage and diarrhea, were collected.

\section{CYP3A5*3 Genotyping}

The CYP3A5*3 6986A $>\mathrm{G}$ was detected by fluorescence staining in situ hybridization (FISH). In brief, PHARMGENE SNP analysis sample preservation solution and PHARM-GENE 200 SNP analysis sample processing solution (Beijing SINO-ERA JIYIN Tech) were added to peripheral blood leukocytes collected from peripheral blood. Then, the samples were detected on a fluorescence detector (Xi'an Tianlong Technology, TL998A).

\section{Effectiveness Evaluation}

Therapeutic effectiveness was divided into complete remission (CR), partial remission (PR) or no remission (NR). CR was defined as proteinuria $<0.5 \mathrm{~g} /$ day with normal renal function and PR was defined as proteinuria of $0.5-3.5 \mathrm{~g}$ /day that had declined to $\leq 50 \%$ of the baseline levels with stable renal function. If neither CR nor PR was achieved after 24 weeks of initial treatment, the outcome was defined as NR.

\section{Statistical Analysis}

Variables were presented as mean \pm standard deviation (SD). Statistical difference between two groups was determined with a Student's $t$-test. And those of non-normal distribution were tested by the Wilcoxon rank-sum test. Kruskal-Wallis test was used to perform comparisons among the different groups. The independent samples $T$-test was used to compare the means of two samples. $\chi^{2}$ test was used to compare the disorder classified data. Categorical variables were compared using the Kruskal-wallis test when appropriate. Correlation analysis was calculated using Pearson and Spearman correlation coefficients. The logistic regressive analysis was applied to pinpoint the independent risk factors of the incidence of side effects. A $p$ value $<0.05$ was considered significant. The statistical analysis was performed using SPSS 19.0 software (Chicago, Ill., USA).

\section{Results}

\section{Baseline Characteristics}

A total of 88 patients fulfilled the selection criteria, of whom 65 (73.86\%) were men and 23 (26.14\%) were women. The mean age was $49.98 \pm 15.64$ years (between 14 and 83 years old). The mean body weight was $70.7 \pm 11.13 \mathrm{~kg}$ (Table 1). The most common observed variant for CYP3A5 was CYP3A5 *3/*3 $(51.14 \%)$. CYP3A5 $* 1 / * 3$ was seen in $46.59 \%$ patients. CYP3A5 *1/*1 only accounted for $2.27 \%$ (2 cases) (Figure 1). Twelve patients lost follow-up or changed treatment, so 76 patients who completed follow-up were included in the final analysis (Table 2). They were divided into two groups: CYP3A5 nonexpresser (CYP3A5*3/*3) and CYP3A5 expresser (CYP3A5*1/*3). Baseline demographics were presented in Table 2, and there was no significant difference in baseline data between the two groups.

\section{Relationship Between CYP3A5 Phenotype and TAC Concentration}

As shown in Table 3, although TAC dose and dose/weight in CYP3A5 expresser group were markedly elevated, the blood concentration and $\mathrm{C}_{0} / \mathrm{D}$ ratio were still lower than the levels in CYP3A5 nonexpresser group $(p<0.05)$. Twelve patients in the CYP3A5 expresser group did not achieve the recommended TAC concentration in the follow-up periods due to the complications or economic conditions. Only three patients in the CYP3A5 nonexpresser group had unsatisfied blood concentration. 
Table I General Clinical Data for Enrolled Patients with IMN

\begin{tabular}{|c|c|}
\hline Characteristic & Value \\
\hline Cases (male, \%) & $88(65,73.86 \%)$ \\
\hline Body weight (kg) & $70.7 \pm 11.13$ \\
\hline Age (years) & $49.98 \pm 15.64$ \\
\hline \multirow[t]{3}{*}{ CYP3A5 phenotypes (Cases, \%) } & CYP3A5 $* 3 / * 3$ a $(45,51.14 \%)$ \\
\hline & CYP3A5 $* 1 / * 3{ }^{b}(4 I, 46.59 \%)$ \\
\hline & CYP3A5 $* 1 / * I{ }^{b}(2,2.27 \%)$ \\
\hline \multirow[t]{3}{*}{ Lost to follow-up (Cases) } & CYP3A5 $* 3 / * 3$ a $(3)$ \\
\hline & CYP3A $5 * 1 / * 3{ }^{b}(6)$ \\
\hline & CYP3A5 $* 1 / * I^{b}(I)$ \\
\hline \multirow[t]{3}{*}{ Treatment regimen changed (Cases) } & CYP3A5 $* 3 / * 3$ a $(1)$ \\
\hline & CYP3A5 $* 1 / * 3^{b}(0)$ \\
\hline & CYP3A $5 * 1 / * 1{ }^{b}(I)$ \\
\hline
\end{tabular}

Notes: Data were presented as means \pm SD. ${ }^{a}$ Homozygous carriers of CYP3A $5 * 3$ (CYP3A5 nonexpresser); ${ }^{b}$ Allele carriers of the CYP3A5*I (CYP3A5*I/*I or CYP3A $5 * 1 / * 3$, CYP3A5 expresser).

\section{Correlation Between $C_{0} / D$ and Clinical Characteristics}

To investigate the correlation between $\mathrm{C}_{0} / \mathrm{D}$ and clinical characters, the associations of clinical indexes such as age, gender, albumin, hemoglobin, and hematocrit value with $\mathrm{TAC}_{0} / \mathrm{D}$ ratio were studied. As shown in Table 4, body weight, hemoglobin, and serum uric acid level were positively correlated with $\mathrm{C}_{0} / \mathrm{D}$ ratio $(p<0.05)$.

\section{Comparison of the Efficacy Between Two Groups}

The total response rate $(\mathrm{CR}+\mathrm{PR})$ in $\mathrm{CYP} 3 \mathrm{~A} 5$ nonexpresser group was slightly higher than that in CYP3A5 expresser group after 24 weeks of treatment, but there was no statistical difference between the two groups $(p>0.05)$ (Table 5).

\section{Incidence of Adverse Events}

A total of 43 case-times patients exhibited adverse effects, 11 suffered infection especially severe pneumonia, 10 suffered hyperuricemia, 9 suffered glucose intolerance (Table 6). The infection rate in the CYP3A5 nonexpresser group (21.95\%) was remarkably higher than the rate in the CYP3A5 expresser group $(5.71 \%)(p<0.05)$. There were no significant differences between the two groups in terms of the incidences of other adverse events. Notably, kidney function decline

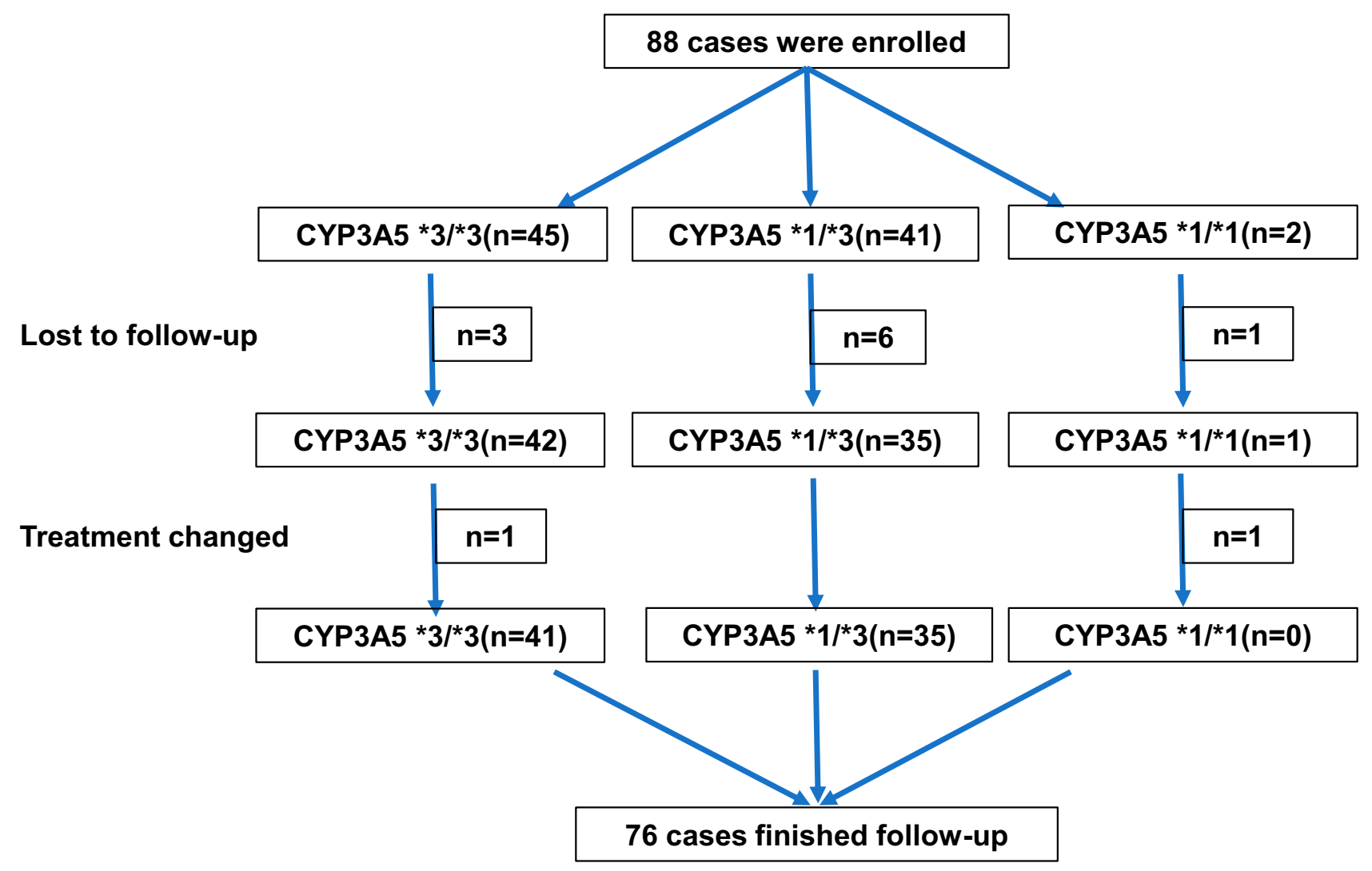

Figure I CYP3A5 genotype screening of the enrolled IMN patients.

Abbreviation: IMN, idiopathic membranous nephropathy. 
Table 2 Comparison of the Clinical Characteristics Between Groups

\begin{tabular}{|c|c|c|c|}
\hline Characteristic & $\begin{array}{l}\text { CYP3A5 } \\
\text { Nonexpresser }\end{array}$ & $\begin{array}{l}\text { CYP3A5 } \\
\text { Expresser }\end{array}$ & $\mathbf{p}$ \\
\hline $\begin{array}{l}\text { CYP3A5 } \\
\text { phenotypes (Cases) }\end{array}$ & $\begin{array}{l}\text { CYP3A5 } * 3 / * 3^{a} \\
(4 I)\end{array}$ & $\begin{array}{l}\text { CYP3A5 *1/*3 } \\
\mathrm{b}(35)\end{array}$ & \\
\hline Age (year) & $50.66 \pm 13.89$ & $47.89 \pm 16.49$ & 0.429 \\
\hline $\begin{array}{l}\text { Gender (Male/ } \\
\text { female) }\end{array}$ & $33 / 8$ & $22 / 13$ & 0.123 \\
\hline Weight (kg) & $72.70 \pm 11.73$ & $68.84 \pm 9.98$ & 0.131 \\
\hline Leukocyte $\left(* 10^{9} / \mathrm{L}\right)$ & $7.81 \pm 1.95$ & $7.03 \pm 1.70$ & 0.071 \\
\hline $\begin{array}{l}\text { Lymphocyte }\left(* 10^{9} /\right. \\
\text { L) }\end{array}$ & $2.00 \pm 0.67$ & $2.02 \pm 0.56$ & 0.918 \\
\hline Hemoglobin $(g / L)$ & $129.07 \pm 20.92$ & $130.17 \pm 21.12$ & 0.821 \\
\hline Platelet $\left(* 10^{9} / \mathrm{L}\right)$ & $239.5 I \pm 73.06$ & $228.09 \pm 41.53$ & 0.416 \\
\hline Albumin $(g / L)$ & $22.74 \pm 5.96$ & $22.11 \pm 5.79$ & 0.811 \\
\hline Globulin (g/L) & $22.04 \pm 4.12$ & $20.7 I \pm 2.55$ & 0.101 \\
\hline $\begin{array}{l}\text { Serum Glucose } \\
(\mathrm{mmol} / \mathrm{L})\end{array}$ & $5.21 \pm 0.94$ & $4.86 \pm 0.70$ & 0.068 \\
\hline $\begin{array}{l}\text { Urea nitrogen } \\
(\mathrm{mmol} / \mathrm{L})\end{array}$ & $6.49 \pm 2.4 \mathrm{I}$ & $5.72 \pm 1.82$ & 0.229 \\
\hline $\begin{array}{l}\text { Serum Creatinine } \\
(\mu \mathrm{mol} / \mathrm{L})\end{array}$ & $84.68 \pm 19.59$ & $76.03 \pm 19.46$ & 0.058 \\
\hline Uric acid $(\mu \mathrm{mol} / \mathrm{L})$ & $389.66 \pm 101.24$ & $366.92 \pm 82.40$ & 0.292 \\
\hline $\begin{array}{l}\text { 24h urine protein } \\
\text { (g) }\end{array}$ & $9.09 \pm 7.49$ & $6.84 \pm 5.20$ & 0.059 \\
\hline $\begin{array}{l}\text { eGFR }(\mathrm{mL} / \mathrm{min} / \\
\left.1.73 \mathrm{~m}^{2}\right)\end{array}$ & $88.11 \pm|8.7|$ & $95.5 I \pm 19.80$ & 0.099 \\
\hline Histological grading & & & \\
\hline Stage I & 7 & 7 & NS \\
\hline Stage II & 22 & 17 & \\
\hline Stage III & 9 & 8 & \\
\hline Stage IV & 3 & 3 & \\
\hline $\operatorname{ALT}(\mathrm{u} / \mathrm{L})$ & $20.02 \pm 8.54$ & $21.00 \pm 11.74$ & 0.963 \\
\hline $\operatorname{AST}(\mathrm{u} / \mathrm{L})$ & $20.74 \pm 5.63$ & $22.32 \pm 9.92$ & 0.684 \\
\hline $\begin{array}{l}\text { Cholesterol (mmol/ } \\
\text { L) }\end{array}$ & $7.65 \pm 2.34$ & $8.12 \pm 2.31$ & 0.207 \\
\hline $\begin{array}{l}\text { Triglyceride (mmol/ } \\
\text { L) }\end{array}$ & $3.24 \pm 2.11$ & $2.58 \pm 1.09$ & 0.297 \\
\hline $\begin{array}{l}\text { Anti-PLA2R level } \\
(\mathrm{RU} / \mathrm{mL})\end{array}$ & $202.86 \pm 472.32$ & $154.03 \pm 440.84$ & 0.917 \\
\hline \multicolumn{4}{|l|}{$\begin{array}{l}\text { Tissue PLA2R } \\
\text { staining }\end{array}$} \\
\hline Negative & 10 & 12 & NS \\
\hline Positive & 31 & 23 & \\
\hline
\end{tabular}

Notes: Data were presented as means \pm SD. ${ }^{a}$ Homozygous carriers of CYP3A5*3

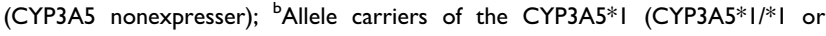
CYP3A5 $* 1 / * 3$, CYP3A5 expresser).

Abbreviations: AST, aspartate aminotransferase; ALT, alanine aminotransferase.

was observed in one patient of the CYP3A5 expresser group whose TAC concentration reached to $21 \mathrm{ng} / \mathrm{mL}$. The renal function was recovered as the TAC concentration reduced to
Table 3 Comparison of the TAC Dose and the Concentration Between Two Groups

\begin{tabular}{|l|l|l|l|}
\hline Groups & $\begin{array}{l}\text { CYP3A5 } \\
\text { Nonexpresser }\end{array}$ & $\begin{array}{l}\text { CYP3A5 } \\
\text { Expresser }\end{array}$ & $\mathbf{P}$ \\
\hline Cases & 41 & 35 & \\
Dose (mg) & $2.54 \pm 0.88$ & $3.79 \pm 0.89$ & $0.000^{*}$ \\
Weight $(\mathrm{kg})$ & $72.70 \pm 11.73$ & $68.84 \pm 9.98$ & 0.131 \\
Dose/Weight (mg/ & $0.036 \pm 0.013$ & $0.056 \pm 0.013$ & $0.000^{*}$ \\
$\mathrm{~kg} / \mathrm{day})$ & & $4.68 \pm 3.09$ & $0.006^{*}$ \\
Blood & $6.48 \pm 2.40$ & & \\
concentration (ng/ & & $84.4 \mathrm{I} \pm 53.99$ & $0.000^{*}$ \\
$\mathrm{~mL})$ & $199.18 \pm 102.72$ & & \\
$\mathrm{C} / \mathrm{D}$ & & & \\
$(\mathrm{ng} / \mathrm{mL} / \mathrm{mg} / \mathrm{kg} / \mathrm{day})$ & & & \\
\hline
\end{tabular}

Notes: ${ }^{*} \mathrm{p}$ value $<0.05$. Data were presented as means \pm SD.

Table 4 Correlation Between $C_{0} / D$ and Clinical Characteristics

\begin{tabular}{|l|l|l|}
\hline & $\mathbf{R}$ & $\mathbf{p}$ \\
\hline Body weight $(\mathrm{kg})$ & 0.24 & $0.039 *$ \\
Hemoglobin $(\mathrm{g} / \mathrm{L})$ & 0.30 & $0.009 *$ \\
Uric acid $(\mu \mathrm{mol} / \mathrm{L})$ & 0.24 & $0.04 I^{*}$ \\
\hline
\end{tabular}

Note: $*_{p}$ value $<0.05$

Table 5 Comparison of the Efficacy Between Two Groups

\begin{tabular}{|l|l|l|l|}
\hline Groups & $\begin{array}{l}\text { CYP3A5 } \\
\text { Nonexpresser }\end{array}$ & $\begin{array}{l}\text { CYP3A5 } \\
\text { Expresser }\end{array}$ & P \\
\hline Cases & 41 & 35 & \\
CR & $11(26.83 \%)$ & $10(28.57 \%)$ & 0.417 \\
PR & $20(48.78 \%)$ & $15(42.86 \%)$ & \\
NR & $8(19.51 \%)$ & $10(28.57 \%)$ & \\
Death & $2(4.88 \%)$ & 0 & \\
\hline
\end{tabular}

Abbreviations: CR, complete remission; PR, partial remission; NR, no remission.

the recommended concentration. None of the patients withdrew from the study because of side effects.

\section{Risk Factors of Adverse Effects Related to TAC}

Logistic regression analysis was performed to explore the risk factors (gender, age, weight, dosage, and CYP3A5 genotypes) for adverse reactions in IMN patients treated with TAC, which indicated that blood concentration and $\mathrm{C}_{0} / \mathrm{D}$ levels of TAC were the key risk factors for adverse events in our study $(p<0.05)$. There were higher mean drug levels $(6.64 \pm 3.26 \mathrm{ng} / \mathrm{mL}$ vs $4.93 \pm 2.31 \mathrm{ng} / \mathrm{mL})$ and mean $\mathrm{C}_{0} / \mathrm{D}$ levels (180.38 \pm 120.45 vs $\left.117.91 \pm 72.44\right)$ in patients with adverse reactions compared with patients without 
Table 6 Comparison of Adverse Events During the 24-Week Study Period Between Two Groups

\begin{tabular}{|l|l|l|l|}
\hline Groups & $\begin{array}{l}\text { CYP3A5 } \\
\text { Nonexpresser }\end{array}$ & $\begin{array}{l}\text { CYP3A5 } \\
\text { Expresser }\end{array}$ & P \\
\hline $\begin{array}{l}\text { Infection } \\
\text { Gastrointestinal } \\
\text { reactions } \\
\text { Hepatic }\end{array}$ & $\begin{array}{l}9(21.95 \%) \\
\text { insufficiency }\end{array}$ & $\begin{array}{l}2(5.71 \%) \\
\text { I (2.86\%) }\end{array}$ & $\begin{array}{l}0.045^{*} \\
0.652\end{array}$ \\
$\begin{array}{l}\text { Hyperuricemia } \\
\text { Glucose } \\
\text { intolerance }\end{array}$ & $4(9.76 \%)$ & $3(8.57 \%)$ & 0.859 \\
$\begin{array}{l}\text { Tremors } \\
\text { Acute kidney } \\
\text { injury }\end{array}$ & $5(12.20 \%)$ & $6(17.14 \%)$ & 0.342 \\
$\begin{array}{l}\text { Unexplained } \\
\text { death }\end{array}$ & $1(2.44 \%)$ & $0(11.43 \%)$ & 0.918 \\
\hline
\end{tabular}

Note: ${ }^{*} \mathrm{p}$ value $<0.05$.

side effects $(p<0.01)$. In addition, the incidence of adverse reactions was positively correlated with blood concentration and $\mathrm{C}_{0} / \mathrm{D}$ levels of TAC. That is, the incidence of adverse effects increased along with the increase of the TAC concentration and $\mathrm{C}_{0} / \mathrm{D}$ level. Other factors had no statistical correlations with adverse reactions $(p>0.05)$ (Figure 2).

\section{Discussion}

IMN is the most common cause of idiopathic nephrotic syndrome in adults and one of the leading identifiable causes of end-stage renal disease (ESRD). ${ }^{16}$ In recent years, various autoantibodies, including M-type phospholipase A2 receptor (PLA2R) and thrombospondin type 1 domain-containing 7A (THSD7A), have been identified as important mechanisms for the pathogenesis of IMN. ${ }^{17}$ Accepted regimens for IMN include steroids/cyclophosphamide, calcineurin inhibitors, and B cell depletion. Early treatment can reduce the complication associated with nephrotic syndrome and prevent progression to ESRD. ${ }^{18}$

TAC has been shown to decrease proteinuria, reduce the rate of loss of renal function, and decrease anti-PLA2R antibody levels in IMN. ${ }^{6,10,16}$ The advantages of TAC include the lower incidence of infection and malignancy compared with cytotoxic drugs and the efficacy when used as monotherapy. ${ }^{3,8,16}$ TAC induced partial or complete remissions in up to $80 \%$ of cases of IMN within 12 months and might be used when cyclophosphamide/steroid treatment was unsuccessful. ${ }^{3,8,19,20}$ The disadvantages include longterm nephrotoxicity with the consequent need to closely monitor blood drug concentrations, increased incidence of hypertension and diabetes, and more importantly, a narrow therapeutic index and a large interindividual difference in both pharmacokinetics and pharmacodynamics. Therapeutic drug monitoring (TDM) and CYP3A5 genotyping are common tools for the adjustment of individual TAC dosage in the clinic. $^{12,13}$ However, TDM is labor-intensive because this method requires frequent monitoring of drug concentrations in blood. Notably, TDM cannot predict individual dosage. Some patients might experience adverse effects before starting drug monitoring. ${ }^{12,13}$ CYP3A5 genotyping can help to optimize the TAC dose between CYP3A5 expressers and non-expressers. Our study confirmed that CYP3A5 polymorphisms were associated with variability in TAC pharmacokinetics, thus affecting the therapeutic efficacy and adverse effects in IMN. Firstly, CYP3A5 polymorphism-guided dosing helped to determine appropriate doses of TAC in IMN. Patients with the CYP3A5 nonexpresser genotype exhibited a $\mathrm{C}_{0} / \mathrm{D}$ ratio 2 times higher than CYP3A5 expressers, suggesting that the genotypes participated in the metabolism of TAC and patients with CYP3A5 expresser required higher doses to achieve target blood concentrations. The dosemodifying effect caused by CYP3A5 polymorphism was further supported by the results that Dose/Weight in CYP3A5 nonexpresser genotype was significantly lower when compared with expressers. These results were consistent with the findings observed in kidney transplant recipients. ${ }^{13}$ Secondly, we found that clinical parameters such as body weight, blood uric acid and hemoglobin were positively associated with the $\mathrm{TAC} \mathrm{C}_{0} / \mathrm{D}$ ratio. As previously reported, body mass index (BMI) $\geq 25$ was proved as one of the risk factors for being slow metabolizers and therefore requiring small TAC doses. ${ }^{21}$ Although the mechanisms underlying the relationship between hyperuricemia and TAC $\mathrm{C}_{0} / \mathrm{D}$ ratio are limited, TAC was reported to reduce uric acid excretion and increase blood uric acid levels. ${ }^{22}$ The initial Dose/Weight in patients with metabolic abnormalities is suggested to be started at relatively lower levels since these patients have a higher risk of TAC over-dosage-related toxicity. Hemoglobin has been reported to be associated with TAC pharmacokinetics in previous studies. ${ }^{23,24}$ This association of hemoglobin with TAC pharmacokinetics could be ascribed to the distribution of TAC, particularly its wide distribution in erythrocytes and plasma proteins. ${ }^{24}$ Although body weight, blood uric acid, and hemoglobin had effects on TAC $\mathrm{C}_{0} / \mathrm{D}$ ratio, CYP3A5 was still the most important factor affecting TAC concentration because there were no differences in these factors between the two groups. 

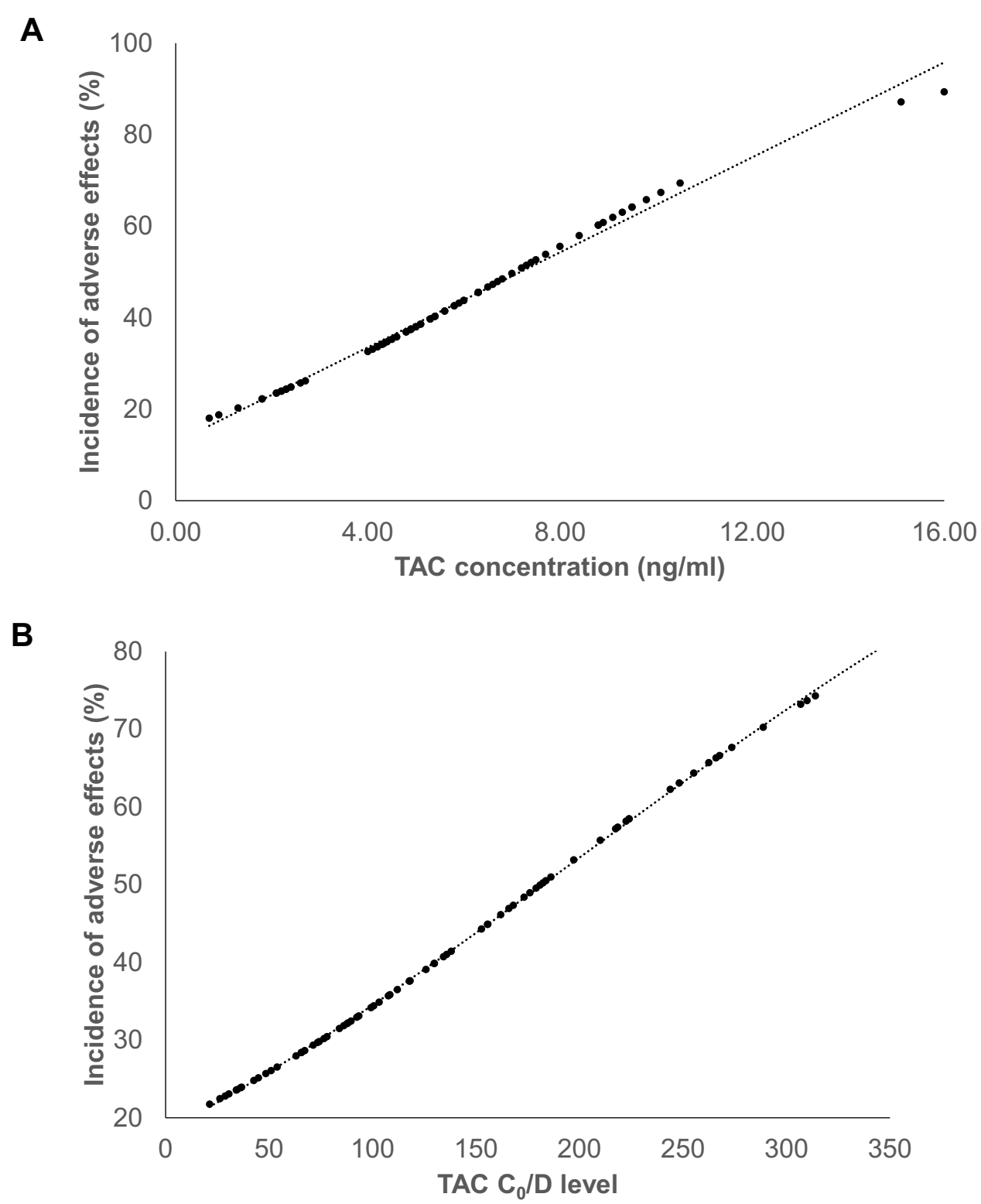

Figure 2 Logistic regression relationships of incidences of adverse effects with TAC and $C_{0} / D$ levels. (A) TAC concentration and (B) $C_{0} / D$ levels were positively correlated with the incidence of adverse reactions. TAC, tacrolimus, $C_{0} / D$, TAC blood concentration divided by daily dose per body weight.

Although the overall response rate in CYP3A5 nonexpresser group was higher than that in CYP3A5 expresser group after 24 weeks of treatment, our results showed that CYP3A5 gene polymorphism had no significant effect on the curative effect of TAC in IMN since there was no statistical difference in the remission rate $(\mathrm{CR}+\mathrm{PR})$ between CYP3A5 nonexpresser and CYP3A5 expresser groups. However, the results regarding side effects differed. It was observed that the infection rate of CYP3A5 nonexpresser was significantly higher than that of CYP3A5 expresser, which might be correlated with the higher TAC blood concentration in CYP3A5 nonexpresser. Besides, a severe adverse event was recorded in a patient with the CYP3A5 nonexpresser genotype who died of secondary pulmonary infection. Meanwhile, the result of the logistic regression analysis indicated that the blood concentration of TAC was the key risk factor for adverse reactions in our study. Therefore, therapeutic drug monitoring was essential to prevent side effect especially in patients with the CYP3A5 nonexpresser genotype. In addition, a patient with the expresser genotype exhibited TAC-related acute nephrotoxicity when the TAC concentration reached to $21 \mathrm{ng} / \mathrm{mL}$, and the renal function was improved along with the concentration decreased. This was consistent with the standpoint that 
acute kidney injury prevailed when TAC concentration was over $20 \mathrm{ng} / \mathrm{mL} .^{25}$ Our study also showed that the incidence of adverse effects increased by $5.19 \%$ for every $1 \mathrm{ng} / \mathrm{mL}$ increase in TAC concentration. The increase of TAC concentration might be associated with a better achievement of treatment effect. However, the incidence of side effects was elevated. Therefore, the optimal dose was suggested to be further reduced in the CYP3A5 non-expressor group in IMN. The previous study by Tang et al also suggested that a low TAC starting dose could be safe to avoid the occurrence of side effects in Chinese renal transplantation recipients. ${ }^{26}$ Further studies are also needed to verify the satisfied concentration range of TAC which can achieve a therapeutic effect and minimize adverse effects.

There were some other limitations in this study, including the retrospective nature of the analysis and a small number of patients. Larger cohorts will be needed to confirm our findings. Furthermore, a short follow-up was likely to underestimate the remission rate since some patients might need more than 6 months to achieve remission of proteinuria. Previous studies demonstrated that anti-PLA2R antibody titers could respond faster than proteinuria to treatment. $^{27,28}$ We observed that the decrease in antiPLA2R antibody titers preceded proteinuria response in some patients. The anti-PLA2R antibody in the remission group usually turned negative within 3 months, while it remained abnormal at 6 months in no remission group. However, anti-PLA2R antibody was not listed as a routine testing item and only 20 patients had this data in the present study. Other factors might also influence the exposure of TAC, including co-administration of other drugs, such as angiotensin-converting enzyme inhibitors (ACEIs), angiotensin receptor blocker (ARBs), proton pump inhibitors (PPIs) and steroids. The potential interactions need to be investigated to predict the TAC dose more precisely. More specifically, a prospective study may be needed to further address these possible clinical consequences, which can be divided into four groups: CYP3A5 expressor group $(0.05 \mathrm{mg} / \mathrm{kg})$, CYP3A5 non-expressor group $(0.05 \mathrm{mg} / \mathrm{kg})$, CYP3A5 non-expressor group $(0.04 \mathrm{mg} / \mathrm{kg})$, CYP3A5 nonexpressor group $(0.03 \mathrm{mg} / \mathrm{kg})$. The aim is to observe the time required for each group to reach the target concentration range and the times of drug adjustments, and to compare the difference in response rate and side effects between different concentration ranges $<4 \mathrm{ng} / \mathrm{mL}, 4-6 \mathrm{ng} / \mathrm{mL}, 6-8 \mathrm{ng} /$ $\mathrm{mL}, 8-10 \mathrm{ng} / \mathrm{mL},>10 \mathrm{ng} / \mathrm{mL}$. Exploring the starting dose and targeting concentration based on CYP3A5 genotypes might be benefit for the IMN patients from the treatment of TAC.
During the follow-up, the response rate of both anti-PLA2Rantibodies and proteinuria are valuable indicators to predict the treatment effect.

Our study paved the way for linking the genetic polymorphisms with the variability of TAC and treatment effect in IMN patients. The whole blood concentrations and $\mathrm{C}_{0} / \mathrm{D}$ ratio levels of TAC in IMN patients were not entirely determined by the dosage and they were also influenced by CYP3A5 genetic polymorphisms. Moreover, the adverse event was associated with blood concentration, $C_{0} / D$ levels. CYP3A5 expressor in IMN resulted in a need for a higher mean TAC daily dose to achieve the target drug exposure, but with fewer side effects. Therefore, CYP3A5 genetic polymorphism was warranted for TAC dosing adjustment to optimize the treatment for patients with IMN.

\section{Acknowledgments}

This work was supported by grants from the Natural Science Foundation of Jiangsu (BK20191075 to Suyan Duan), Chinese Society of Nephrology (17010090678), the Clinic Research Center of Jiangsu Province (No. BL2014080) and the Priority Academic Program Development of Jiangsu Higher Education Institutions.

\section{Disclosure}

The authors declare that they have no conflicts of interest in this work.

\section{References}

1. Li LS, Liu ZH. Epidemiologic data of renal diseases from a single unit in China: analysis based on 13,519 renal biopsies. Kidney Int. 2004;66 (3):920-923. doi:10.1111/j.1523-1755.2004.00837.x

2. Zhou FD, Zhao MH, Zou WZ, Liu G, Wang H. The changing spectrum of primary glomerular diseases within 15 years: a survey of 3331 patients in a single Chinese centre. Nephrol Dial Transplant. 2009;24 (3):870-876. doi:10.1093/ndt/gfn554

3. Chapter 7: idiopathic membranous nephropathy. Kidney Int Suppl (2011). 2012;2(2):186-197. doi:10.1038/kisup.2012.20

4. van den Brand JA, van Dijk PR, Hofstra JM, Wetzels JF. Long-term outcomes in idiopathic membranous nephropathy using a restrictive treatment strategy. $J$ Am Soc Nephrol. 2014;25(1):150-158. doi:10.1681/ASN.2013020185

5. Khan S, Bolton WK. Balancing cancer risk and efficacy of using cyclophosphamide to treat idiopathic membranous nephropathy. Clin J Am Soc Nephrol. 2014;9(6):1001-1004. doi:10.2215/CJN.04130414

6. Howman A, Chapman TL, Langdon MM, et al. Immunosuppression for progressive membranous nephropathy: a UK randomised controlled trial. Lancet. 2013;381(9868):744-751. doi:10.1016/S01406736(12)61566-9

7. Fervenza FC, Appel GB, Barbour SJ, et al. Rituximab or cyclosporine in the treatment of membranous nephropathy. N Engl J Med. 2019;381 (1):36-46. doi:10.1056/NEJMoa1814427 
8. Cattran DC, Brenchley PE. Membranous nephropathy: integrating basic science into improved clinical management. Kidney Int. 2017;91(3):566-574. doi:10.1016/j.kint.2016.09.048

9. Cattran DC, Appel GB, Hebert LA, et al. Cyclosporine in patients with steroid-resistant membranous nephropathy: a randomized trial. Kidney Int. 2001;59(4):1484-1490. doi:10.1046/j.15231755.2001.0590041484.x

10. Praga M, Barrio V, Juarez GF, Luno J, Grupo espanol de estudio de la nefropatia M. Tacrolimus monotherapy in membranous nephropathy: a randomized controlled trial. Kidney Int. 2007;71(9):924-930. doi:10.1038/sj.ki.5002215

11. Westhoff TH, van der Giet M. Tacrolimus in the treatment of idiopathic nephrotic syndrome. Expert Opin Investig Drugs. 2007;16 (7):1099-1110. doi:10.1517/13543784.16.7.1099

12. Luo X, Zhu LJ, Cai NF, Zheng LY, Cheng ZN. Prediction of tacrolimus metabolism and dosage requirements based on CYP3A4 phenotype and CYP3A5(*)3 genotype in Chinese renal transplant recipients. Acta Pharmacol Sin. 2016;37(4):555-560. doi:10.1038/ aps.2015.163

13. Rojas L, Neumann I, Herrero MJ, et al. Effect of CYP3A5*3 on kidney transplant recipients treated with tacrolimus: a systematic review and meta-analysis of observational studies. Pharmacogenomics J. 2015;15(1):38-48. doi:10.1038/tpj.2014.38

14. Haufroid V, Wallemacq P, VanKerckhove V, et al. CYP3A5 and ABCB1 polymorphisms and tacrolimus pharmacokinetics in renal transplant candidates: guidelines from an experimental study. Am J Transplant. 2006;6(11):2706-2713. doi:10.1111/j.1600-6143.2006.01518.x

15. Xu J, Zhang W, Xu Y, et al. Tacrolimus combined with corticosteroids in idiopathic membranous nephropathy: a randomized, prospective, controlled trial. Contrib Nephrol. 2013;181:152-162. doi:10.1159/000348475

16. Cattran D, Brenchley P. Membranous nephropathy: thinking through the therapeutic options. Nephrol Dial Transplant. 2017;32(suppl_1): i22-i29. doi:10.1093/ndt/gfw404

17. Hoxha E, von Haxthausen F, Wiech T, Stahl RAK. Membranous nephropathy-one morphologic pattern with different diseases. Pflugers Arch. 2017;469(7-8):989-996. doi:10.1007/s00424-0172000-4
18. Couser WG. Primary membranous nephropathy. Clin J Am Soc Nephrol. 2017;12(6):983-997. doi:10.2215/CJN.11761116

19. Tran TH, Hughes G, Greenfeld C, Pham JT. Overview of current and alternative therapies for idiopathic membranous nephropathy. Pharmacotherapy. 2015;35(4):396-411. doi:10.1002/phar.1575

20. van de Logt AE, Hofstra JM, Wetzels JF. Pharmacological treatment of primary membranous nephropathy in 2016. Expert Rev Clin Pharmacol. 2016;9(11):1463-1478. doi:10.1080/17512433.2016.1225497

21. Stratta P, Quaglia M, Cena T, et al. The interactions of age, sex, body mass index, genetics, and steroid weight-based doses on tacrolimus dosing requirement after adult kidney transplantation. Eur J Clin Pharmacol. 2012;68(5):671-680. doi:10.1007/s00228-011-1150-0

22. Ben Salem C, Slim R, Fathallah N, Hmouda H. Drug-induced hyperuricaemia and gout. Rheumatology (Oxford). 2017;56(5):679-688. doi:10.1093/rheumatology/kew293

23. Buendia JA, Bramuglia G, Staatz CE. Effects of combinational CYP3A5 $6986 \mathrm{~A}>\mathrm{G}$ polymorphism in graft liver and native intestine on the pharmacokinetics of tacrolimus in liver transplant patients: a meta-analysis. Ther Drug Monit. 2014;36(4):442-447. doi:10.1097/ FTD.0000000000000032

24. Chen D, Guo F, Shi J, et al. Association of hemoglobin levels, CYP3A5, and NR1I3 gene polymorphisms with tacrolimus pharmacokinetics in liver transplant patients. Drug Metab Pharmacokinet 2014;29(3):249-253. doi:10.2133/dmpk.dmpk-13-rg-095

25. Asada A, Bamba S, Morita Y, et al. The effect of CYP3A5 genetic polymorphisms on adverse events in patients with ulcerative colitis treated with tacrolimus. Dig Liver Dis. 2017;49(1):24-28. doi: 10.1016/j.dld.2016.09.008

26. Tang JT, Yan L, Wang LL, et al. A low fixed tacrolimus starting dose is effective and safe in Chinese renal transplantation recipients. Ann Transplant. 2018;23:300-309. doi:10.12659/AOT.907666

27. Hofstra JM, Fervenza FC, Wetzels JF. Treatment of idiopathic membranous nephropathy. Nat Rev Nephrol. 2013;9(8):443-458. doi:10.1038/nrneph.2013.125

28. Waldman M, Austin HA 3rd. Treatment of idiopathic membranous nephropathy. J Am Soc Nephrol. 2012;23(10):1617-1630. doi:10.1681/ ASN.2012010058
Pharmacogenomics and Personalized Medicine

\section{Publish your work in this journal}

Pharmacogenomics and Personalized Medicine is an international, peer-reviewed, open access journal characterizing the influence of genotype on pharmacology leading to the development of personalized treatment programs and individualized drug selection for improved safety, efficacy and sustainability. This journal is indexed on the American Chemical Society's Chemical Abstracts Service (CAS). The manuscript management system is completely online and includes a very quick and fair peer-review system, which is all easy to use. Visit http://www.dovepress.com/testimonials.php to read real quotes from published authors. 